\title{
Fast Low-Temperature Consolidation of AlCoCrFeMnNi High Entropy Alloy
}

\author{
M.A. Ruiz-Esparza-Rodriguez ${ }^{1}$, C.G. Garay-Reyes ${ }^{1}$, I. Estrada-Guel ${ }^{1}$, J.M. Mendoza-Duarte ${ }^{1}$, M.C. \\ Maldonado-Orozco ${ }^{2}$ and R. Martinez-Sanchez ${ }^{1}$.
}

1. Centro de Investigación en Materiales Avanzados (CIMAV), Laboratorio Nacional de Nanotecnología, Miguel de Cervantes 120, 31136 Chihuahua, Chih., México.

2. Universidad Autónoma de Chihuahua, Facultad de ingeniería, Circuito No. 1, Nuevo campus universitario 2 Apdo. postal 1552, C.P. 31240, Chihuahua, Chih., México.

Recently, high entropy alloys (HEA's) have been of great interest to researchers, since they represent a very broad area of study, these alloys are consolidated by different techniques like an arc casting, conventional sintering, plasma sintering and conventional casting [1,2]. A new alternative consolidation route based in high frequency induction has been proposes in this work, such route will provide the option to consolidate HEA's at low temperature and short time, contributing to avoid the growth of grain in nanocrystalline materials, and allowing control porosity and oxidation. Thus, the aim of this work is evaluate the crystalline structure, microstructure, mechanical properties, porosity and density in samples obtained by new fast low temperature consolidation route in the AlCoCrFeMnNi HEA.

The equiatomic AlCoCrFeMnNi powders were obtained by MA. Pure elements (each of them at least 99.9\% purity) were used as the raw material. The millings were performed by using a high energy mill Spex 8000. Milling media and container are done by hardened steel. Milling conditions were set to $10 \mathrm{~h}$ of milling time, powder mass $8.5 \mathrm{~g}$ and a ball-to-powder ratio of 5:1. N-heptane was used as process control agent. To prevent contamination, the balls and vial were coated with nominal composition elemental powders and milling was performed under Ar atmosphere. 2 different routes were used in consolidation process of the powders. The first one was conventional consolidated with the following conditions: the compaction pressure was $1.56 \mathrm{GPa}$ for $10 \mathrm{~min}$, followed by the sintered at $1200^{\circ} \mathrm{C}$ for 3 $\mathrm{h}$. The second one was the fast-low temperature consolidation with the following conditions: compacted and pre-sinterized were performed simultaneously under compaction pressure of $0.9 \mathrm{Gpa}$ at $600^{\circ} \mathrm{C}$ for 3 min using a high frequency induction furnace, posteriorly a sintered was carried out at $1200^{\circ} \mathrm{C}$ for $3 \mathrm{~h}$. the microstructural characterization was carried out by means of a transmission electron microscope JEOL JEM 2200FS+CS and scanning electron microscope HITACHI SU3500. The Vickers microhardness was evaluated in LM300 AT tester.

Figure 1 shows Vickers microhardness values and SEM micrographs obtained in the 2 consolidation routes. A reduction of pores-oxides, a best diffusion process of elements and higher microhardness values using the new route proposed in comparison to conventionally sintering are observed. Figure 2 shows the microstructure for samples consolidated by new route, which is composed of 2 phases: the AlNi-rich phase (dark) with FCC structure, and the FeCo-rich phase (clear) with a BCC structure. In addition, aluminum oxide with nanometic size, darkness tonality and homogeneously distributed in matrix is observed. It is concluded that fast low-temperature consolidation route presents a greater homogeneity of phases in the matrix, which contribute to increase microhardness values and decrease of porosity and oxidation.

References:

[1] D. B. Miracle, O. N. Senkov, Acta Mater 122 (2017) p. 448-511. 
[2] Y. Zhang, T. T. Zuo, Z. Tang, M. C. Gao, K. A. Dahmen, P. K. Liaw, Z. P. Lu, Prog Mater Sci 61 (2014) p. 1-93.

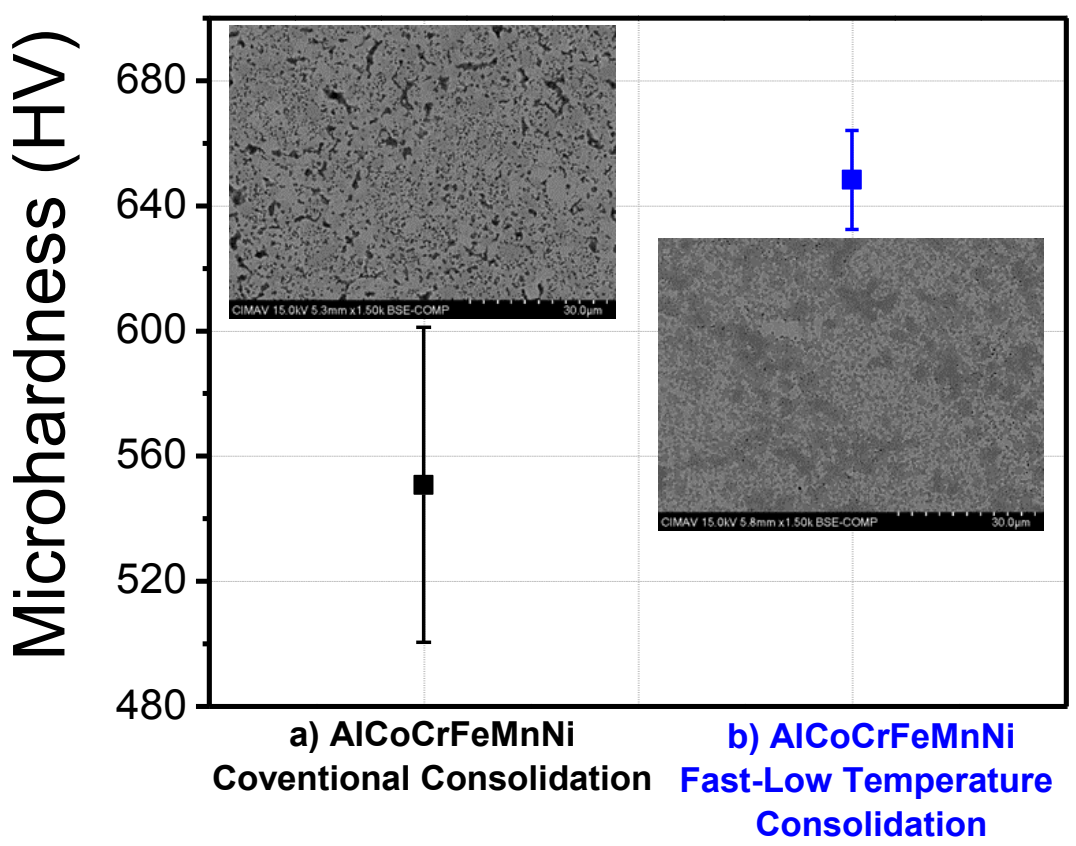

Figure 1. Vickers microhardness values and SEM micrographs obtained in the 2 consolidation routes, a) conventional consolidation and b) fast-low temperature consolidation.

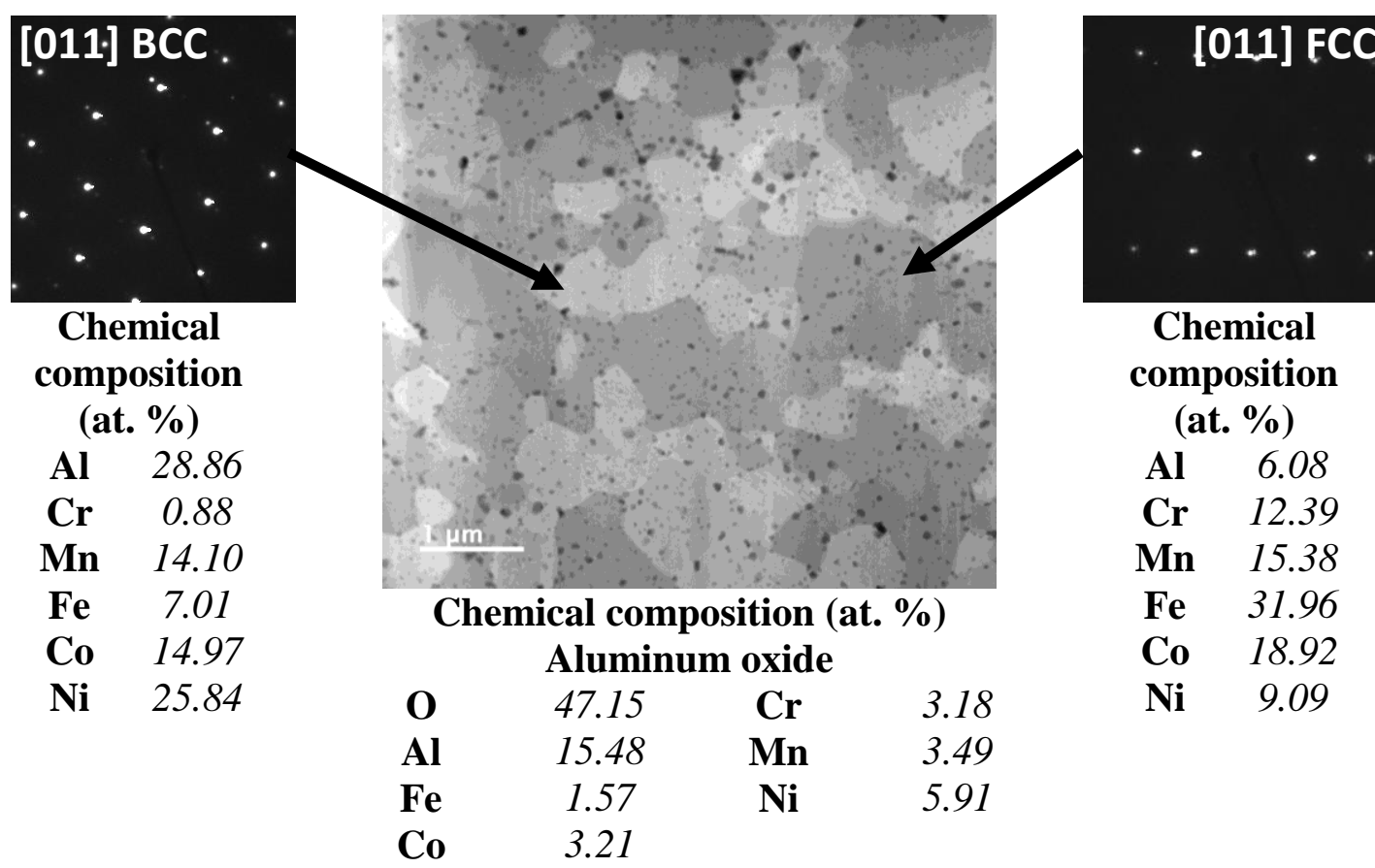

Figure 2. TEM micrograph, SAED and EDS corresponding to phases present in sample obtained by fast low-temperature consolidation route. 